\title{
Examination of Gossypol-Pluronic Micelles as Potential Radiosensitizers
}

\author{
Keishiro Tomoda, ${ }^{1}$ Carol Chiang, ${ }^{1}$ Kevin R. Kozak, ${ }^{2}$ and Glen S. Kwon ${ }^{1,3,4}$
}

Received 22 May 2015; accepted 26 July 2015; published online 6 August 2015

\begin{abstract}
Chemoradiotherapy, the combination of chemotherapy and radiotherapy to treat cancer, has the potential to enhance local therapeutic effects and simultaneously treat systemic disease. However, chemoradiotherapy may also enhance normal tissue effects leading to both acute and late toxicities. Furthermore, subtherapeutic chemoradiotherapy may result in aggressive tumor repopulation. Tumorspecific radiosensitizing chemotherapy may yield a synergistic therapeutic effect and avoid augmentation of normal tissue toxicity. In this study, the radiosensitizing effects of gossypol were investigated. Also, Pluronics were studied for gossypol solubilization and co-radiosensitization effects. Gossypol inhibits Bcl2 and $\mathrm{Bcl}-\mathrm{X}_{\mathrm{L}}$, antiapoptotic proteins that are overexpressed in various cancer cells. Pluronic micelles (P85, F88, L35, and P123) effectively encapsulated gossypol, raising its water solubility by more than 1000-fold. Cytotoxic, anticlonogenic, and radiosensitizing effects were evaluated to characterize gossypol and Pluronic combinations. Gossypol and P85 had the strongest antiproliferative effect on A549 human lung adenocarcinoma cells in a cell viability assay. The $\mathrm{IC}_{50}$ value was seven times lower than gossypol only treatment $(330 \pm 70 \mathrm{nM}$ vs $2400 \pm 400 \mathrm{nM}$, (mean $\pm \mathrm{SE})$ ). Gossypol and P85 showed significant inhibition of clonogenic survival, approximately $30 \%$ inhibition, compared to treatment with gossypol alone. An experimental sequencing study demonstrated greater inhibition of clonogenic survival when drug treatment followed radiation compared to a sequence of drug treatment followed by radiation. These results suggest that Pluronic micelles readily solubilize gossypol and that the combination of gossypol and P85 may augment the therapeutic effects of ionizing radiation.
\end{abstract}

KEY WORDS: chemoradiotherapy; gossypol; Pluronic; polymeric micelles; radiosensitization.

\section{INTRODUCTION}

Surgery, radiotherapy, and chemotherapy are the three major therapies for cancer treatment. Often, a combination of therapies is necessary to increase therapeutic efficacy (1). The addition of chemotherapy to radiotherapy may result in increased local therapeutic effects of radiation while simultaneously addressing systemic disease. Consequently, chemoradiotherapy has emerged as standard first-line treatment for an array of malignancies. However, chemoradiotherapy can also augment normal tissue injury resulting in severe acute side effects. Consequently, a critical issue in the design of novel chemoradiotherapies is the development of combinations that have the capacity to enhance antitumor effects while

\footnotetext{
${ }^{1}$ Pharmaceutical Sciences Division, School of Pharmacy, University of Wisconsin, 777 Highland Avenue, Madison, Wisconsin 53705, USA.

${ }^{2}$ Mercy Regional Cancer Center, 1000 Mineral Point Ave, Janesville, Wisconsin 53548, USA.

${ }^{3}$ Center for Theragnosis, Biomedical Research Institute, Korea Institute of Science and Technology (KIST), Hwarangno14-gil 5, Seongbuk-gu, Seoul, 136-791, Republic of Korea.

${ }^{4}$ To whom correspondence should be addressed. (e-mail: gskwon@pharmacy.wisc.edu)
}

minimizing unwanted normal tissue injury. Tumor-specific radiosensitizing chemotherapy is expected to yield synergistic antitumor effects and minimize side effects (2). Thus, therapeutic agents with both independent, tumor-specific cytotoxic effects and radiosensitizing effects are expected to be excellent candidates for combined modality therapies.

Gossypol, a polyphenolic compound extracted from cotton seed (3), has been reported to radiosensitize various cancer cells (4-8). Gossypol inhibits the effects of antiapoptotic proteins Bcl-2 and Bcl-XL (3-8), which are commonly overexpressed in cancer cells. Although gossypol is expected to enhance radiation-induced apoptosis of cancer cells via this mechanism, gossypol is highly hydrophobic and poorly water soluble, requiring a drug solubilization strategy for IV administration. Previous research has studied gossypol in the context of oral applications in clinical and preclinical studies, but gastrointestinal disturbances have been reported $(3,7,9)$.

Pluronics were selected in this study to solubilize gossypol and enhance its anticancer effects by membrane disruption. Pluronics are triblock copolymers of propylene oxide (PO) and ethylene oxide (EO). They are known to solubilize hydrophobic compounds in the micellar state and have been proven to be effective solubilizers of polyphenols, such as resveratrol, for IV administration (10). Our previous 
study confirmed that Pluronic F68 (poloxamer 188) solubilized gossypol up to $5.4 \pm 0.1 \mathrm{mg} / \mathrm{mL}$ in water (11). Pluronics have been reported to have selective membrane-perturbing effects on cancer cells, according to their PO:EO ratio and chain length $(12,13)$. According to those reports, Pluronics have been categorized into four groups: group I-high HLB, large molecular weight; group II-intermediate HLB, intermediate molecular weight; group IIIa-low HLB, small molecular weight; and group IIIb-low HLB, large molecular weight. Pluronics in groups I and IIIa were reported to have a membrane solidification effect, whereas Pluronics in groups II and IIIb have a membrane fluidization effect (12). P85, one of the Pluronics in group II, was reported to inhibit respiration in mitochondria, deplete ATP, and decrease P-glycoprotein ATPase activity in both multidrug resistant (MDR) cells and non-MDR cells $(12,13)$. More recently, Pluronic L10 was reported to radiosensitize Gli36 human glioma cells by inhibiting heat shock protein (Hsp) 90 and 70 (14). Hsp 90 and 70 , molecular chaperone proteins that are overexpressed in various cancer cells, contribute to the conformational maturation of oncogenic survival signaling proteins and inhibit the apoptotic pathway to protect cancer cells from death (15-18). Therefore, Hsp 90 and 70 are considered novel targets for cancer treatment (19-21). Several reports suggest that Hsp 90 inhibitors show radiosensitizing effects by inhibiting radiation-induced cell survival signals, cell cycle checkpoint activation, and DNA double strand break repair (22-27). However, inhibition of Hsp 90 is reported to trigger the upregulation of Hsp 70. Therefore, dual inhibition of Hsp 90 and 70, such as that exhibited by Pluronic L10, is considered to be more attractive for cancer therapy (28-32). In this study, F88, P85, L35, and P123 were selected as representative Pluronics in group I, II, IIIa, and IIIb, respectively. The effects of Pluronics type, amount, and gossypol concentration on cancer cell viability, clonogenic survival, and radiosensitization were evaluated with the aim of producing a novel and potent micellar radiosensitizer for cancer treatment.

\section{MATERIALS AND METHODS}

\section{Materials}

Racemic gossypol was purchased from LKT Laboratories, Inc. (St. Paul, MN). Pluronic P85, F88, L35, P123 were kindly provided by BASF Corp. (Florham Park, NY). A549 human lung adenocarcinoma cells were purchased from ATCC (Manassas, VA). CellTiter-Blue ${ }^{\circledR}$ Cell Viability Assay kit was purchased from Promega (Madison, WI). Crystal Violet was purchased from Sigma-Aldrich (St. Louis, MO). All other reagents were obtained from Thermo Fisher Scientific Inc. (Fairlawn, NJ) and were of analytical grade.

\section{Methods}

\section{Preparation of Gossypol-Loaded Pluronic Micelles}

Gossypol and Pluronics (P85, F88, L35, and P123) were dissolved in $2.0 \mathrm{~mL}$ of acetone in a round-bottom flask. Acetone was evaporated under reduced pressure at $60^{\circ} \mathrm{C}$. After the evaporation, $1.0 \mathrm{~mL}$ of $0.9 \% \mathrm{NaCl}$ solution was added to rehydrate gossypol and Pluronics. Subsequently, the solution was centrifuged at $13,000 \mathrm{rpm}$ for $5 \mathrm{~min}$ to remove insoluble gossypol and filtered through a $0.2 \mu \mathrm{m}$ sterile syringe filter. Gossypol-loaded Pluronic micelles were prepared at 1:9, 1:19, 1:99, and 1:332 of gossypol:Pluronic weight ratios (i.e., gossypol-loading ratios of Pluronic micelles at 10, 5,1 , and $0.3 \%$, respectively).

\section{Physicochemical Evaluation of Gossypol-Loaded Pluronic Micelles}

Z-average diameter and polydispersity index (PDI) of gossypol-loaded Pluronic micelles at $25^{\circ} \mathrm{C}$ were measured using a Zetasizer Nano-ZS (Malvern Instruments, UK) at a fixed angle of $173^{\circ}$. The loading ratio of gossypol in the prepared gossypol-loaded Pluronic micelles was measured using a reverse-phase Shimadzu Prominence HPLC system (Shimadzu, Japan). Twenty microliters of gossypol-Pluronic micelle solution was dissolved in $980 \mu \mathrm{L}$ of mobile phase $(3: 1$ acetonitrile:aqueous phosphoric acid $(1 \%))$. Ten microliters of the dissolved solution was injected into a Zorbax RX-C8 analytical column $(4.6 \mathrm{~mm} \times 250 \mathrm{~mm}$, particle size $5 \mu \mathrm{m}$, Agilent) with a flow rate of $1.0 \mathrm{~mL} / \mathrm{min}$, a run time of $12 \mathrm{~min}$, and column oven temperature at $40^{\circ} \mathrm{C}$. The separation was conducted in an isocratic mode mobile phase. Gossypol was detected at $373 \mathrm{~nm}$, and its retention time was $8.5 \mathrm{~min}$. The level of gossypol showed linearity at $0.21-210 \mu \mathrm{g} / \mathrm{mL}$ with the limit of detection at $0.2 \mu \mathrm{g} / \mathrm{mL}$.

\section{Cell Viability Assays}

A549 cells were cultured in RPMI 1640 medium supplemented with $10 \%$ fetal bovine serum and $1 \%$ penicillin/streptomycin. A549 cells were maintained at $37^{\circ} \mathrm{C}$ under an atmosphere of $5 \% \mathrm{CO}_{2}$ in a humidified incubator. A549 cells were seeded at 1000 cells/well on 96-well plates and incubated for $24 \mathrm{~h}$. Various ratios (1:9, 1:19, 1:99, and 1:332) of gossypol-loaded Pluronic micelles were evaluated at gossypol concentrations of $1,2,5,10$, and $50 \mu \mathrm{M}$. After $72 \mathrm{~h}$ of incubation, cell viability was determined using a CellTiterBlue ${ }^{\circledR}$ Cell Viability Assay kit according to manufacturer's instructions. $\mathrm{IC}_{50}$ values were calculated from obtained data with use of Graphpad Prism6® software. Gossypol dissolved in DMSO was used as a control. Experiments were performed in triplicate.

\section{Clonogenic Survival Assays}

Effect of Gossypol on A549 Cell Clonogenic Survival. Clonogenic survival assays were performed as previously described (33). Cell radiation was performed using a Shepherd \& Associates Model 109 irradiator (San Fernando, CA) with a 137 cesium source at a dose rate of $3.89 \mathrm{~Gy} / \mathrm{min}$. Lethally irradiated (30 Gy) A549 cells were used to ensure identical total cell seeding for all experiments (2500 cells in $2 \mathrm{~mL}$ media per well). The number of lethally radiated cells and unirradiated cells was as follows: $0 \mathrm{~Gy}$, 2400:100; 2 Gy 2300:200; 4 Gy, 2200:300; 6 Gy 1500:1000; 8 Gy 0:2500. After seeding, cells were incubated for $24 \mathrm{~h}$. After the 24-h incubation, gossypol $(2-4 \mu \mathrm{M})$ dissolved in DMSO was added to the wells (Day 1). Final DMSO level 
was less than or equal to $0.1 \%$. At day 9 , the cultured medium was refreshed once and cells were incubated an additional 3 days. At day 12, the medium was removed and cells were washed once with $2.0 \mathrm{~mL}$ of PBS. Subsequently, cells were stained with a $1.0 \mathrm{~mL}$ of $0.5 \%$ crystal violet/ methanol solution for $15 \mathrm{~min}$ at $37^{\circ} \mathrm{C}$. After staining, the cells were washed with bulk tap water in a sink and naturally dried. Subsequently, the number of colonies was counted using a cutoff of 50 aggregated cells.

Radiosensitizing Effects of Gossypol, Pluronics, and Gossypol-Loaded Pluronic Micelles. The seeding condition of A549 cells was the same as that described in section 2.2.4.1. After 24-h incubation, cells seeded on 6-well plates were treated with $2.0 \mathrm{~mL}$ of gossypol dissolved in DMSO, Pluronic, or gossypol-loaded Pluronic micelles (Day 1) and incubated for $24 \mathrm{~h}$. The concentration of gossypol in the wells was fixed at $2.0 \mu \mathrm{M}$, and the Pluronic level in the wells was fixed at $0.1 \mathrm{mg} / \mathrm{mL}$, in correspondence with a 1:99 weight ratio of gossypol:Pluronic. One day after drug treatment, irradiation was carried out at doses of $0,2,4,6$, and 8 Gy (Day 2). Subsequent procedures were the same as those described in section 2.2.4.1. Survival fraction (SF) was calculated as (observed plating efficiency)/(plating efficiency at 0 Gy). A fitting curve was applied for the SF with a linear-quadratic equation: $S F=\exp \left(\alpha D+\beta D^{2}\right)$, where $D$ is radiation dose (33). From the equation of fitting curve, radiation dose at $50 \%$ cell kill was calculated. Subsequently, the sensitizer enhancement ratio (SER) was calculated as radiation dose without drug/radiation dose with drug.

Effects of Treatment Sequence on Gossypol and P85 Inhibition of Clonogenic Survival. Clonogenic survival assays were performed as described in section 2.2.4.2. The concentration of gossypol and P85 level were fixed at $2.0 \mu \mathrm{M}$ and $0.1 \mathrm{mg} / \mathrm{mL}$, respectively. Drug treatment was performed 48 , 24 and $1 \mathrm{~h}$ prior to radiation as well as 1, 24 and $48 \mathrm{~h}$ after radiation.

\section{Statistical Analysis}

Statistical analysis was performed using Student's $t$ tests. Differences were deemed statistically significant if the twotailed $p$ value was less than 0.05 .

\section{RESULTS AND DISCUSSION}

Physicochemical Evaluation of Gossypol-Loaded Pluronic Micelles

The particle diameter, polydispersity index (PDI), and gossypol-loading ratio of each gossypol-loaded Pluronic micelle are summarized in Table I. For gossypol-loaded P85 micelles, particle diameter was about $20 \mathrm{~nm}$, independent of the gossypol:P85 ratio. The PDI increased with increasing levels of P85. For gossypol-loaded F88 micelles, the particle diameter was slightly larger than for gossypol-loaded P85 micelles except with the highest concentrations of F88. F88 micelle PDI generally decreased with increased gossypol

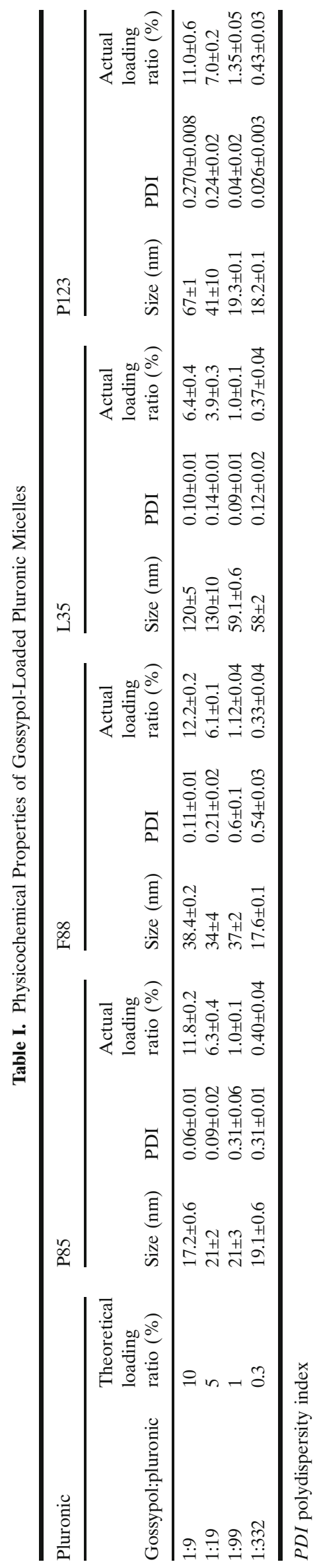


loading. Gossypol-loaded L35 micelles were much larger than gossypol-loaded P85 and F88, (60 to $130 \mathrm{~nm}$ ); particle diameter increased with drug loading. L35 was the only formulation (1:9 of gossypol:L35) that showed markedly lower gossypol-loading efficiency compared to the theoretical loading ratio. These data suggest that the low molecular weight of L35 limits gossypol-loading efficiency at high gossypol concentration. Gossypol-loaded P123 micelles ranged in size from 20 to $70 \mathrm{~nm}$. Micelle size increased with drug loading. In summary, Pluronic micelles, with the exception of gossypol-L35 micelles at a 1:9 ratio of gossypol:L35, efficiently encapsulated gossypol.

Pluronics increased the water solubility of gossypol up to $12 \pm 1 \mathrm{mg} / \mathrm{mL}$ in our study (P85: 9.4 $\pm 0.4, \mathrm{~F} 88: 9.9 \pm 0.1$, L35: 10 \pm 1 , P123: $12 \pm 1 \mathrm{mg} / \mathrm{mL}$ ). Gossypol is known to be extremely water insoluble with a maximum solubility of less than $0.01 \mathrm{mg} / \mathrm{mL}$ (34). Pluronics increased the solubility of gossypol in water more than 1000 -fold. In summary, Pluronic micelle solubilization may be sufficient for intravenous infusion of gossypol. This formulation may permit more compelling preclinical and clinical examination of gossypol (34).

\section{Cell Viability Assay In Vitro}

The $\mathrm{IC}_{50}$ value of gossypol was $2.4 \pm 0.4 \mu \mathrm{M}$ for $\mathrm{A} 549$ cells. L35 did not significantly affect the $\mathrm{IC}_{50}$ values for A549 cells (Fig. 1). F88 slightly decreased $\mathrm{IC}_{50}$ values (2-fold) as the level of Pluronic increased. In contrast, P85 and P123 decreased $\mathrm{IC}_{50}$ values by 7 - and 5 -fold, respectively, as the level of Pluronic increased (Fig. 1). The strongest cytotoxicity was obtained using gossypol and P85 at 1:332 of gossypol:P85. Group II Pluronics with intermediate to high hydrophobicity, such as P85, show cell membrane fluidization effects (12), which cause cell membrane instability and loss of homeostasis. Moreover, P85 is reported to inhibit respiration in mitochondria of cancer cells by affecting the respiratory chain complexes I and IV (13). Respiratory inhibition causes impairment of mitochondrial function, consequently inducing the release of cytochrome C, and onset of apoptosis (13). Thus, gossypol and P85 may induce apoptosis due to Bcl-2 and $\mathrm{Bcl}-\mathrm{X}_{\mathrm{L}}$ inhibition and mitochondrial respiration

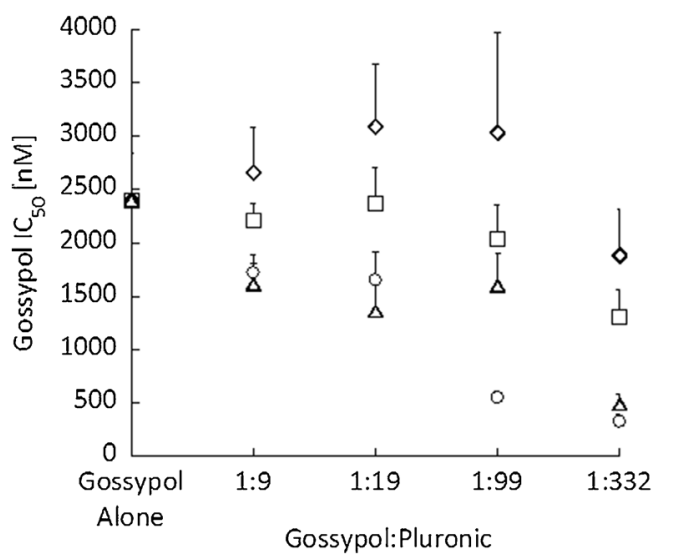

Fig. 1. Cytotoxicity of gossypol and Pluronics against human lung adenocarcinoma A549 cells (open circle P85, open square F88, open diamond $\mathrm{L} 35$, open triangle $\mathrm{P} 123 . \mathrm{N}=3$ )

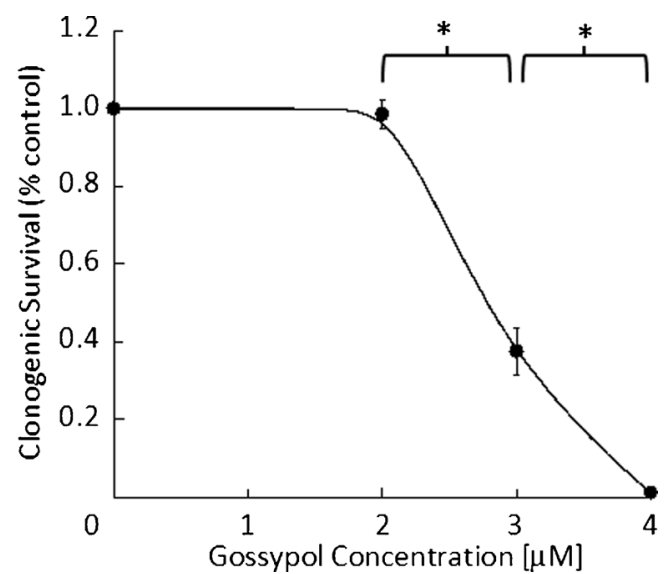

Fig. 2. Gossypol inhibition of A549 clonogenic survival (* $P<0.0001$. $N=3$ )

inhibition, respectively. On the other hand, Pluronics in group I and IIIa do not have any effects on mitochondrial membranes, and Pluronics in group IIIb have less perturbing effect to mitochondrial membrane than Pluronics in group II (12). Thus, P85 (Pluronics in group II) showed higher cytotoxicity than other Pluronics.
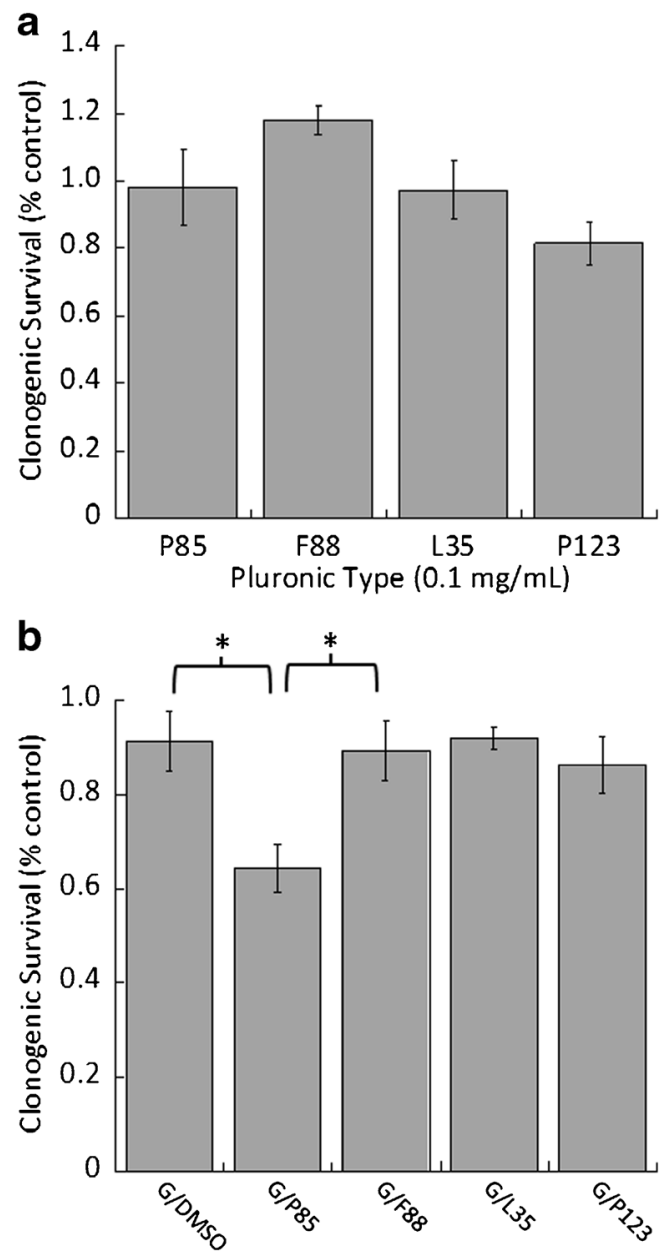

Fig. 3. a Effect of Pluronics on A549 cell clonogenic survival (Pluronics at $0.1 \mathrm{mg} / \mathrm{mL} . \quad N=3$ ). b Effect of Pluronics-solubilized gossypol on A549 cell clonogenic survival ( $G$ gossypol at $2 \mu \mathrm{M}$; $* P<0.05 . N=3$ ) 


\section{Clonogenic Assay In Vitro}

The effect of gossypol on clonogenic survival is shown in Fig. 2. The inhibitory effects of gossypol are dose-dependent and increase sharply above $2 \mu \mathrm{M}$.
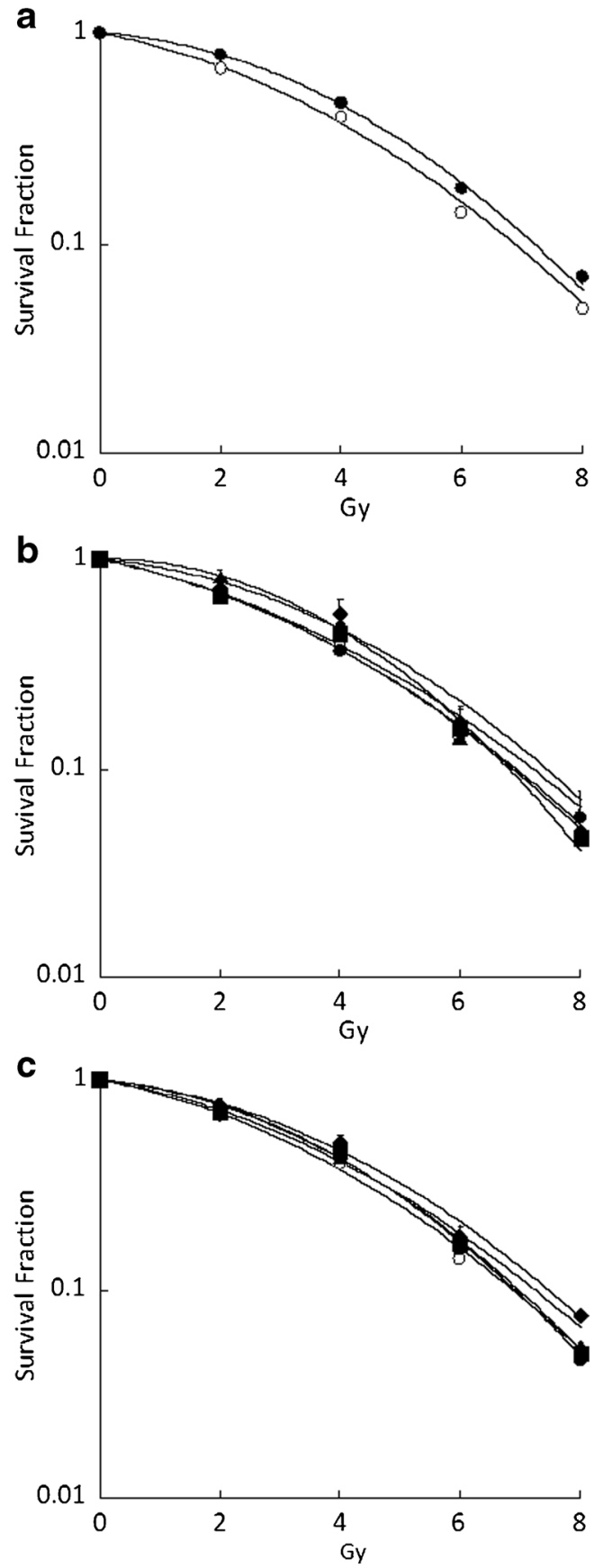

Fig. 4. a Effect of gossypol on A549 radiosensitivity (black circle gossypol at $2 \mu \mathrm{M}$ in DMSO, open circle XRT only. $N=3$ ). b Effect of Pluronics $(0.1 \mathrm{mg} / \mathrm{mL})$ on A549 radiosensitivity (black circle P85, black square F88, black diamond L35, black triangle $\mathrm{P} 123$, open circle XRT only. $N=3$ ). c Effect of Pluronics-solubilized gossypol on A549 radiosensitivity (gossypol at $2 \mu \mathrm{M}$, Pluronics at $0.1 \mathrm{mg} / \mathrm{mL}$ : black circle gossypol+P85, black square gossypol+F88, black diamond gossypol+L35, black triangle gossypol+P123, open circle XRT only. $N=3$ )
Table II. The SER Values of Gossypol Alone, Pluronics Alone, and Pluronics-Solubilized Gossypol

\begin{tabular}{lllll}
\hline Gossypol alone & 0.84 & & & \\
\hline & P85 & F88 & L35 & P123 \\
Pluronics & 1.01 & 0.98 & 0.83 & 0.83 \\
Gossypol/Pluronics & 0.89 & 0.93 & 0.84 & 0.9 \\
\hline
\end{tabular}

The effect of different Pluronics alone on A549 clonogenic survival is shown in Fig. 3a. The effect of both DMSO- and Pluronics-solubilized gossypol on A549 clonogenic survival is shown in Fig. 3b. Gossypol at $2 \mu \mathrm{M}$ and Pluronics alone at $0.1 \mathrm{mg} / \mathrm{mL}$ did not significantly inhibit A549 clonogenic survival. Similarly, gossypol $(2 \mu \mathrm{M})$ solubilized in F88, L35, and P123 failed to show statistically significant inhibition of A549 clonogenic survival. Only when gossypol was solubilized in P85 was inhibition of clonogenic survival observed.

To assess potential radiosensitizing effects of gossypol, different Pluronics, and different Pluronics-solubilized gossypol, A549 cells were treated with these agents for $24 \mathrm{~h}$ and then subjected to ionizing radiation (0-8 Gy). As shown in Fig. 4, no radiosensitization was observed, contrasting with earlier data on Pluronic L10 (14). The
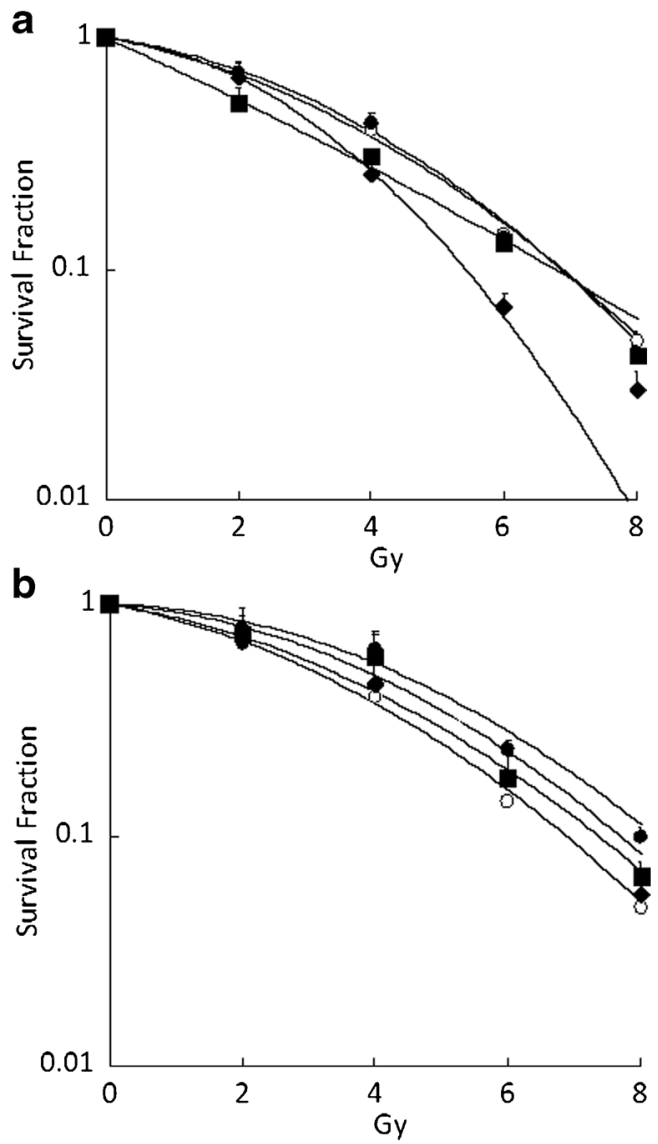

Fig. 5. Effect of gossypol, Pluronic P85, and Pluronic P85 solubilized gossypol on A549 radiosensitivity. A549 cells were treated a $1 \mathrm{~h}$ or b $48 \mathrm{~h}$ prior to radiation. (gossypol at $2 \mu \mathrm{M}, \mathrm{P} 85$ at $0.1 \mathrm{mg} / \mathrm{mL}$, black circle gossypol, black square $\mathrm{P} 85$, black diamond gossypol+P85, open circle XRT only. $N=3$ ) 
SER value of gossypol alone was 0.84. Also, the SER value of P85, F88, L35, and P123 were 1.01, 0.98, 0.83, and 0.83 , respectively. Similarly, the SER value of P85, F88, L35, and P123-solubilized gossypol were 0.89, 0.93, 0.84 , and 0.90 , respectively (Table II). These data confirmed mathematically that no radiosensitization was observed in those groups.

To assess if potential radiosensitization was dependent on the duration of cell exposure to gossypol, cells were treated for 1 or $48 \mathrm{~h}$ with gossypol, Pluronic P85 or gossypol-containing Pluronic P85 micelles prior to radiation. Similar to $24 \mathrm{~h}$ pretreatment, no significant radiosensitization was observed at 8 Gy with 1 or 48 -h pretreatment (Fig. 5a, b). SER values for 1 -h pretreatment with DMSO-solubilized gossypol (0.95) and 48-h
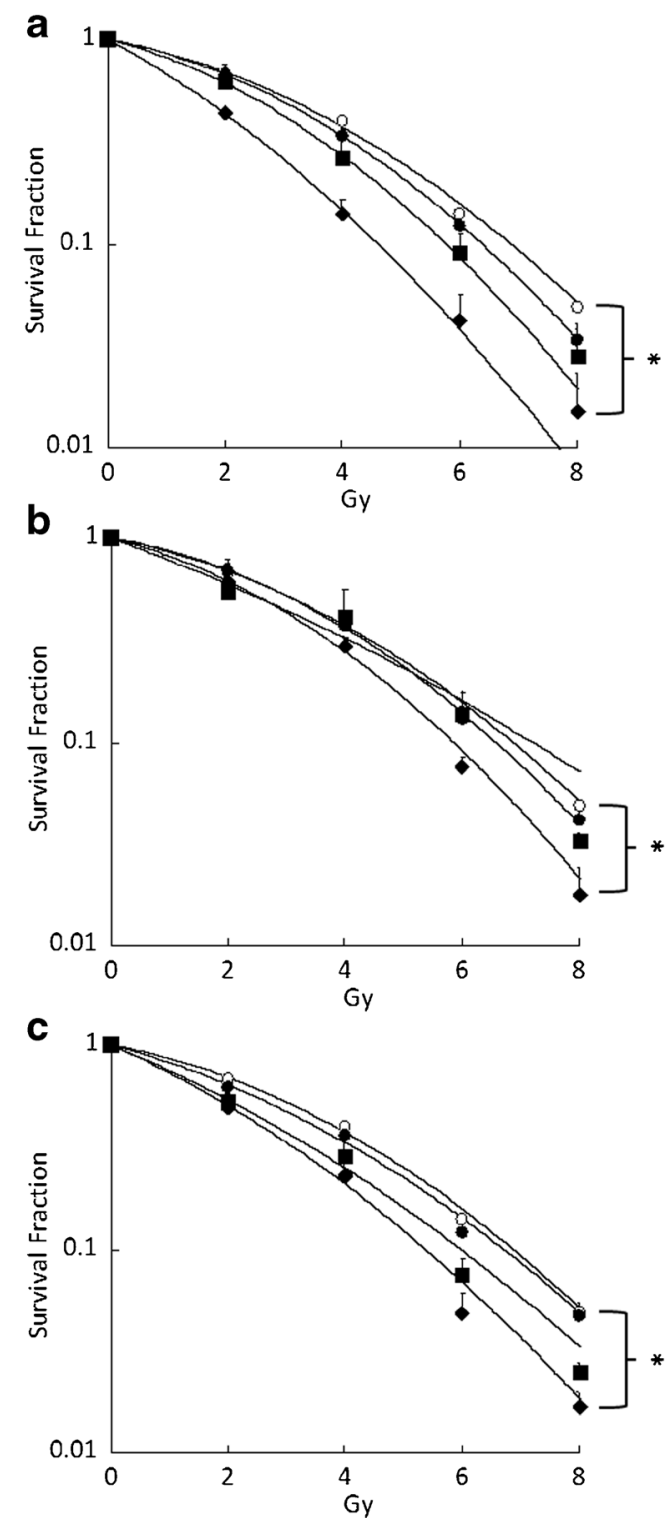

Fig. 6. Effect of gossypol, Pluronic P85, and Pluronic P85 solubilized gossypol on A549 radiosensitivity. Radiated cells were treated a $1 \mathrm{~h}, \mathbf{b}$ $24 \mathrm{~h}$, or $\mathbf{c} 48 \mathrm{~h}$ after radiation (gossypol at $2 \mu \mathrm{M}$, P85 at $0.1 \mathrm{mg} / \mathrm{mL}$, black circle gossypol, black square $\mathrm{P} 85$, black diamond gossypol+P85, open circle XRT only. $N=3$ )
Table III. The SER Values of Gossypol Alone, P85 Alone, and P85Solubilized Gossypol

\begin{tabular}{llccc}
\hline & Interval (h) & Gossypol & P85 & $\begin{array}{l}\text { P85-solubilized } \\
\text { gossypol }\end{array}$ \\
\hline Pretreatment & 1 & 0.95 & 1.42 & 1.14 \\
& 24 & 0.84 & 1.01 & 0.89 \\
Post-treatment & 48 & 0.72 & 0.80 & 0.92 \\
& 1 & 1.06 & 1.23 & 1.86 \\
& 24 & 1.01 & 1.21 & 1.20 \\
& 48 & 1.12 & 1.42 & 1.55 \\
\hline
\end{tabular}

pretreatment with DMSO-solubilized gossypol (0.72), P85 (0.80), and P85-solubilized gossypol (0.92) showed no radiosensitization. SER values for 1 -h pretreatment with P85 and P85-solubilized gossypol showed slight radiosensitization (1.42 and 1.14 , respectively).

To determine if therapy sequence impacted clonogenic survival, A549 cells were first subjected to ionizing radiation (0-8 Gy) then treated with control media, gossypol in DMSO, Pluronic P85, or Pluronic P85 micelles containing gossypol $(1,24$, and $48 \mathrm{~h}$ after radiation). As seen in Fig. 6, post-radiation treatment of A549 cells with P85 micelles containing gossypol resulted in a statistically significant augmentation of radiation cell kill at $8 \mathrm{~Gy}$. No such radiosensitization was observed with gossypol alone or P85 alone. The SER values of the post-treatment group document greater radiosensitization than those of the pretreatment group (Table III). The highest SER value recorded was for P85-solubilized gossypol $1 \mathrm{~h}$ following cell radiation (1.86). In general, gossypol treatment following radiation appeared to be more effective in augmenting radiation cell kill. Although the molecular mechanisms for this unique pattern of radiosensitization are still under further investigation, the results of clonogenic assays reflect cell killing, as opposed to inhibition of cell proliferation as assessed in the cell viability assays. Thus, tumor cell killing may be facilitated by a combination of radiation and gossypol-P85 treatment.

\section{CONCLUSION}

Gossypol was successfully solubilized by P85, F88, L35, and P123 Pluronic micelles using a solvent evaporation method. P85 solubilized gossypol showed the strongest cancer cell cytotoxicity in this study. Gossypol $(2 \mu \mathrm{M})$ alone, Pluronics $(0.1 \mathrm{mg} / \mathrm{mL})$ alone, and gossypol $(2 \mu \mathrm{M})$ in F88, L35, and P123 micelles did not show anticlonogenic effects. Only gossypol $(2 \mu \mathrm{M})$ solubilized in P85 micelles showed anticlonogenic effects. The anticlonogenic effects of gossypol were concentration dependent. The combination of gossypol and P85 augmented radiation cell kill uniquely when drug treatment followed cell radiation. In summary, gossypol-loaded P85 micelles may be an attractive candidate for combination with ionizing radiation, and these data will help guide further examination. Additional studies are needed to clarify the mechanism by which gossypol-loaded P85 
micelles radiosensitize cancer cells and evaluate the performance of this novel nanoparticle in vivo.

\section{REFERENCES}

1. American Cancer Society: What are the different types of cancer treatment? http://www.cancer.org/treatment/understanding yourdiagnosis/talkingaboutcancer/whensomeoneyouknow hascancer/when-somebody-you-know-has-cancer-cancer-treatment-questions. Accessed 22 Jan 2015.

2. Werner ME, Foote MB, Wang AZ. Chemoradiotherapy of human tumors: novel approaches from nanomedicine. Curr Pharm Des. 2012;18(19):2830-7.

3. Wang X, Howell CP, Chen F, Yin J, Jiang Y. Gossypol-A polyphenolic compound from cotton plant. Adv Food Nutr Res. 2009;58:215-63. doi:10.1016/S1043-4526(09)58006-0.

4. Pisula UK, Windhorst S, Daphi JD, Mayr G, Dikomey E. Radiosensitization of tumour cell lines by the polyphenol Gossypol results from depressed double-strand break repair and not from enhanced apoptosis. Radiother Oncol. 2007;83:296-303. doi:10.1016/j.radonc.2007.04.024.

5. Zerp SF, Stoter R, Kuipers G, Yang D, Lippman ME, Blitterswijk WJV, et al. AT-101, a small molecule inhibitor of anti-apoptotic Bcl-2 family members, activates the SAPK/JNK pathway and enhances radiation-induced apoptosis. Radiat Oncol. 2009;4:47-56.

6. Moretti L, Li B, Kim KW, Chen H, Lu B. AT-101, a Pan-Bcl-2 inhibitor, leads to radiosensitization of non-small cell lung cancer. J Thorac Oncol. 2010;5(5):680-7.

7. Xu L, Yang D, Wang S, Tang W, Liu M, Davis M, et al. (-)Gossypol enhances response to radiation therapy and results in tumor regression of human prostate cancer. Mol Cancer Ther. 2005;4:197-205.

8. Wang J, Jin L, Li X, Deng H, Chen Y, Lian Q, et al. Gossypol induces apoptosis in ovarian cancer cells through oxidative stress. Mol Biosyst. 2013;9(6):1489-97. doi:10.1039/c3mb25461e.

9. Baggstrom MQ, Qi Y, Koczywas M, Argiris A, Johnson EA, Millward MJ, et al. A phase II study of AT-101 (gossypol) in chemotherapy-sensitive recurrent extensive stage small cell lung cancer (ES-SCLC). J Thorac Oncol. 2011;6(10):1757-60. doi:10.1097/JTO.0b013e31822e2941.

10. Kenealey JD, Subramanian L, Ginkel PRV, Darjatmoko S, Lindstrom MJ, Somoza V, et al. Resveratrol metabolites do not elicit early pro-apoptotic mechanisms in neuroblastoma cells. J Agric Food Chem. 2011;59:4979-86. doi:10.1021/jf104901g.

11. Kwon GS, Shin HC, Cho H. Inventor; Wisconsin Alumni Research Foundation, assignee. Micelles for the Solubilization of Gossypol. United States patent US 20120321715A1. 2012.

12. Batrakova EV, Li S, Alakhov VY, Miller DW, Kabanov AV. Optimal structure requirements for Pluronic block copolymers in modifying p-glycoprotein drug efflux transporter activity in bovine brain microvessel endothelial cells. J Pharmacol Exp Ther. 2003;304(2):845-54. doi:10.1124/jpet.102.043307.

13. Alakhova DY, Rapoport NY, Batrakova EV, Timoshin AA, Li S, Nicholls D, et al. Differential metabolic responses to Pluronic in MDR and non-MDR cells: a novel pathway for chemosensitization of drug resistant cancers. J Control Release. 2010;142:89-100. doi:10.1016/j.jconrel.2009.09.026.

14. Perera RH, Patel R, Wu H, Gangolli M, Traughber B, Oleinick $\mathrm{N}$, et al. Preclinical evaluation of radiosensitizing activity of Pluronic block copolymers. Int J Radiat Biol. 2013;89(10):80112. doi:10.3109/09553002.2013.800246.

15. Whitesell L, Lindquist SL. HSP90 and the chaperoning of cancer. Nat Rev Cancer. 2005;5:761-72. doi:10.1038/nrc1716.

16. Kamal A, Thao L, Sensintaffar J, Zhang L, Boehm MF, Fritz LC, et al. A high-affinity conformation of Hsp90 confers tumour selectivity on Hsp90 inhibitors. Nature. 2003;425:407-10.
17. Workman P, Powers MV. Chaperoning cell death: a critical dual role for Hsp90 in small-cell lung cancer. Nat Chem Biol. 2007;3(8):455-7.

18. Morano KA. New tricks for an old dog the evolving world of Hsp70. N Y Acad Sci. 2007;1113:1-14. doi:10.1196/ annals.1391.018.

19. Laszlo A, Thotala D, Hallahan DE. Membrane phospholipids, EML4-ALK, and Hsp90 as novel targets in lung cancer treatment. Cancer J. 2013;19(3):238-46.

20. Granato M, Lacconi V, Peddis M, Lotti LV, Renzo LD, Gonnella $\mathrm{R}$, et al. HSP70 inhibition by 2-phenylethynesulfonamide induces lysosomal cathepsin D release and immunogenic cell death in primary effusion lymphoma. Cell Death Dis. 2013;4:e730. doi:10.1038/cddis.2013.263.

21. Galluzzi L, Giordanetto F, Kroemer G. Targeting HSP70 for cancer therapy. Mol Cell. 2009;36:176-7. doi:10.1016/ j.molcel.2009.10.003.

22. Kabakov AE, Makarova YM, Malyutina YV. Radiosensitization of human vascular endothelial cells through Hsp90 inhibition with 17-N-allylamino-17-demethoxygeldanamycin. Int $\mathbf{J}$ Radiat Oncol Biol Phys. 2008;71(3):858-65. doi:10.1016/ j.ijrobp.2008.02.034.

23. Stoeltzing O. Dual-targeting of $\mathrm{mTOR}$ and HSP90 for cancer therapy. Cell Cycle. 2010;9(11):2051-2.

24. Kim WY, Oh SH, Woo JK, Hong WK, Lee HY. Targeting heat shock protein 90 overrides the resistance of lung cancer cells by blocking radiation-induced stabilization of hypoxia-inducible factor-1 $\alpha$. Cancer Res. 2009;69(4):1624-32. doi:10.1158/00085472.CAN-08-0505.

25. Enomoto A, Fukasawa T, Takamatsu N, Ito M, Morita A, Hosoi Y, et al. The HSP90 inhibitor 17-allylamino-17demethoxygeldanamycin modulates radiosensitivity by downregulating serine/threonine kinase 38 via Sp1 inhibition. Eur J Cancer. 2013;49:3547-58. doi:10.1016/j.ejca.2013.06.034.

26. Camphausen K, Tofilon PJ. Inhibition of Hsp90: a multitarget approach to radiosensitization. Clin Cancer Res. 2007;13:432630. doi:10.1158/1078-0432.CCR-07-0632.

27. Noguchi M, Yu D, Hirayama R, Ninomiya Y, Sekine E, Kubota $\mathrm{N}$, et al. Inhibition of homologous recombination repair in irradiated tumor cells pretreated with Hsp90 inhibitor 17allylamino-17-demethoxygeldanamycin. Biochem Biophys Res Commun. 2006;351:658-63. doi:10.1016/j.bbrc.2006.10.094.

28. McConnell JR, McAlpine SR. Heat shock proteins 27, 40, and 70 as combinational and dual therapeutic cancer targets. Bioorg Med Chem Lett. 2013;23:1923-28. doi:10.1016/ j.bmcl.2013.02.014.

29. Cui XB, Yu ZY, Wang W, Zheng YQ, Liu W, Li LW. CoInhibition of HSP70/HSP90 synergistically sensitizes nasopharyngeal carcinoma cells to thermotherapy. Integr Cancer Ther. 2012;11(1):61-7. doi:10.1177/1534735411399900.

30. Miyagawa T, Saito H, Minamiya Y, Mitobe K, Takashima S, Takahashi $\mathrm{N}$, et al. Inhibition of $\mathrm{Hsp} 90$ and 70 sensitizes melanoma cells to hyperthermia using ferromagnetic particles with a low Curie temperature. Int J Clin Oncol. 2014;19(4):72230. doi:10.1007/s10147-013-0606-x.

31. Wang RE. Targeting heat shock proteins $70 / 90$ and proteasome for cancer therapy. Curr Med Chem. 2011;18:4250-64.

32. Ma L, Sato F, Sato R, Matsubara T, Hirai K, Yamasaki M, et al. Dual targeting of heat shock proteins 90 and 70 promotes cell death and enhances the anticancer effect of chemotherapeutic agents in bladder cancer. Oncol Rep. 2014;31(6):2482-92. doi:10.3892/or.2014.3132.

33. Franken NAP, Rodermond HM, Stap J, Haveman J, van Bree C. Clonogenic assay of cells in vitro. Nat Protoc. 2006;1(5):2315-9. doi:10.1038/nprot.2006.339.

34. Yan F, Cao XX, Jiang HX, Zhao XL, Wang JY, Lin YH, et al. A novel water-soluble gossypol derivative increases chemotherapeutic sensitivity and promotes growth inhibition in colon cancer. J Med Chem. 2010;53:5502-10. doi:10.1021/ jm1001698. 